\title{
Níveis de proteína bruta e energia metabolizável na ração para codornas de corte ${ }^{1}$
}

\author{
Almir Chalegre de Freitas ${ }^{2}$, Maria de Fátima Freire Fuentes ${ }^{3}$, Ednardo Rodrigues Freitas ${ }^{4}$, \\ Francislene Silveira Sucupira ${ }^{5}$, Bruno César Moura de Oliveira $^{6}$, Gastão Barreto Espíndola ${ }^{3}$ \\ ${ }^{1}$ Parte da tese apresentada pelo primeiro autor ao PDIZ/UFC para obtenção do grau de Doutor em Zootecnia. Financiada pela FUNCAP \\ 2 UFRPE (Unidade Acadêmica de Garanhuns). \\ ${ }^{3}$ Departamento de Zootecnia/CCA/UFC \\ ${ }^{4}$ Departamento de Zootecnia/CCA/UFC. \\ ${ }^{5}$ Curso de Zootecnia/CCA/UFC. Bolsista do CNPq \\ ${ }^{6}$ Curso de Agronomia/CCA/UFC.
}

RESUMO - Avaliou-se o efeito de diferentes níveis de PB (20, 22, 24 e 26\%) e EM $(2.565,2.715,2.865$ e $3.015 \mathrm{kcal} / \mathrm{kg})$ na ração sobre o desempenho de codornas de corte. Foram utilizadas 768 codornas européias (Coturnix coturnix coturnix), machos e fêmeas no período de 1 a 42 dias de idade, distribuídas em delineamento inteiramente casualizado, com os tratamentos em arranjo fatorial $4 \times 4$ (proteína $\times$ energia), com três repetições de 16 aves. Não houve efeito significativo da interação proteína $\times$ energia nem dos níveis de PB sobre o consumo de ração, o ganho de peso e a conversão alimentar das aves e a viabilidade econômica das rações. Entretanto, o aumento do nível de energia da ração provocou redução linear no consumo de ração, aumentou o ganho de peso e melhorou a conversão alimentar das aves. O consumo de ração por codornas de corte depende do nível de energia da ração. O melhor desempenho destas aves foi obtido com $20 \%$ de PB e $2.865 \mathrm{kcal} \mathrm{de}$ EM/kg

Palavras-chave: Coturnix coturnix coturnix, codornas européias, consumo de ração, conversão alimentar, produção de carne

\section{Dietary crude protein and metabolizable energy levels for meat quails}

\begin{abstract}
The effect of different CP $(20,22,24$, and 26\% of CP) and ME $(2,565,2,715,2,865$, and 3,015 kcal of $\mathrm{ME} / \mathrm{kg}$. ) levels on the performance of meat quails was evaluated. Seven hundred and sixty-eight European quails (Coturnix coturnix coturnix) of both sexes from 1 to 42 days of age were assigned to a completely randomized design with $4 \times 4$ factorial arrangement (protein $\mathrm{x}$ energy) and grouped into three clusters with 16 birds each. No significant interaction among proteinenergy and protein levels on feed intake, weight gain, feed:gain ratio and viability was observed. However, increasing the dietary energy level resulted in linear reduction of feed intake and greater weight gain and feed:gain ratio. Feed intake of meat quails depends on the dietary energy level. Diet containing $20 \% \mathrm{CP}$ and $2,865 \mathrm{kcal} \mathrm{ME} / \mathrm{kg}$ account for better meat quail performance.
\end{abstract}

Key Words: Coturnix coturnix coturnix, European quails, feed intake, feed:gain ratio, meat production

\section{Introdução}

A carne de codorna é uma fonte de proteína de excelente qualidade e com grande aceitação em todas as camadas sociais. Murakami \& Ariki (1998) afirmaram que a coturnicultura de corte é muito expressiva na Europa, principalmente na região do Mediterrâneo. No Brasil, a produção de ovos é mais representativa, mas, em virtude da elevada taxa de crescimento e do reduzido consumo de ração, a produção de codornas de corte pode constituir uma nova alternativa para o setor avícola (Oliveira et al., 2002).

A coturnicultura, assim como outras atividades avícolas, é desenvolvida visando à produção de proteína de origem animal com o menor custo possível. Entre os fatores que incidem sobre o custo de produção de codornas, a alimentação pode representar mais de $70 \%$ do custo total. Portanto, existe uma preocupação por parte dos nutricionistas em oferecer às aves rações com níveis nutricionais mais adequados, que propiciem melhor desempenho e, conseqüentemente, maior retorno econômico.

Segundo Pinto et al. (2002), no Brasil, a formulação das rações para codornas tem sido realizada com base nas exigências nutricionais descritas pelo NRC (1994), segundo o qual codornas nas fases inicial e de crescimento devem receber rações com $24 \%$ de PB e $2.900 \mathrm{kcal}$ de EM/kg de ração. Entretanto, segundo esses autores, esses valores não são apropriados para as condições tropicais e, portanto, são necessárias pesquisas para determinação das exigên- 
cias nutricionais para as aves nessas condições. De acordo com Garcia (2002), a escassez de pesquisas sobre exigências nutricionais para codornas é um dos fatores que limitam a exploração racional para a produção de carne.

Resultados de trabalhos realizados em clima tropical e subtropical por Shrivastav \& Panda (1999) utilizando codornas de corte (Coturnix coturnix) indicam que essas aves devem receber ração com $27 \%$ de PB na fase inicial (0 a 2 semanas) e $24 \%$ de PB na fase de crescimento (3 a 5 semanas) e que o nível de EM deve ser de $2.800 \mathrm{kcal} / \mathrm{kg}$ de ração para ambas as fases. Martins (2002) ressalta ainda que são poucas as instituições nas quais se utiliza este tipo de ave e que a variação do material genético existente no mercado consiste em uma das barreiras no desenvolvimento dessa atividade.

Oliveira (2001a,b) avaliou o efeito de quatro níveis de PB $(20,22,24$ e $26 \%)$ em rações isoenergéticas $(2.900 \mathrm{kcal}$ de $\mathrm{EM} / \mathrm{kg}$ ) sobre o desempenho produtivo de codornas de corte italianas, de ambos os sexos, no período de 1 a 49 dias de idade. De acordo com o autor, os níveis de proteína utilizados não influenciaram as características estudadas.

Avaliando o efeito do plano nutricional e do sexo sobre o rendimento de carcaça de codornas de corte, Silva et al. (2003) notaram que, apesar do maior peso vivo das fêmeas, os machos apresentam maior rendimento de carcaça $(72,2 \mathrm{x}$ $68,4 \%$ ), provavelmente em virtude do maior desenvolvimento do aparelho reprodutivo da fêmea. Os dados obtidos também demonstraram que os efeitos da deficiência protéica são mais expressivos nas fêmeas, influenciando o peso vivo e o rendimento de carcaça, o que confirma a necessidade de estudos sobre o manejo alimentar dessas aves por separação de sexo. De acordo com esses pesquisadores, o nível de PB da ração de codornas de corte machos e fêmeas pode ser reduzido de 28 para $22,4 \%$ no período de 1 a 21 dias de idade (crescimento) e de 24 para $19,2 \%$ no período de 22 a 42 dias de idade.

Nesta pesquisa, avaliaram-se os efeitos de diferentes níveis de PB e EM na ração sobre o desempenho de codornas de corte no período de 1 a 42 dias de idade, em condições tropicais.

\section{Material e Métodos}

O experimento foi realizado no Setor de Avicultura do Departamento de Zootecnia/CCA da Universidade Federal do Ceará - UFC no período de 13 de setembro a 24 de outubro de 2002.

Foram utilizadas 768 codornas européias (Coturnix coturnix coturnix) no período 1 a 42 dias de idade, alojadas em um galpão de alvenaria $(15 \times 10 \mathrm{~m})$ coberto com telhas de barro, com piso cimentado, pé-direito de 3,5 m, orientado longitudinalmente no sentido leste-oeste. $\mathrm{O}$ galpão era dividido em 48 boxes $(0,65 \times 1,00 \mathrm{~m}), 24$ de cada lado, separados por um corredor central com 1,00 $\mathrm{m}$ de largura. Foram utilizadas 16 codornas (metade de cada sexo) por boxe, em uma densidade de 24,6 aves $/ \mathrm{m}^{2}$.

Durante os primeiros dias, a água foi oferecida em bebedouros tipo pressão (capacidade para $3 \mathrm{~L}$ ), que, no $10^{\circ}$ dia, foram substituídos por bebedouros pendulares com nível constante de água. A limpeza dos bebedouros foi realizada duas vezes ao dia durante todo o período experimental.

A ração foi fornecida em comedouros tipo bandeja, os quais foram substituídos, também no $10^{\circ}$ dia, por comedouros tubulares tipo infantil para frangos de corte, com capacidade para $5 \mathrm{~kg}$. A distribuição das rações nos comedouros tipo bandeja foi feita duas vezes ao dia, em quantidade suficiente para reduzir ao máximo o desperdício. Nos comedouros tubulares, no entanto, a ração foi disponibilizada em quantidade suficiente para vários dias, sendo revolvida várias vezes ao dia para estimular o consumo pelas aves.

A iluminação artificial do galpão foi feita desde o primeiro dia do experimento, por meio de lâmpadas fluorescentes distribuídas a 2,40 m do piso, permitindo iluminação uniforme em todos os boxes (22 lúmens $/ \mathrm{m}^{2}$ ), com fotoperíodo de 24 horas de luz/dia (natural + artificial), visando incentivar o consumo de ração.

As codornas foram vacinadas contra a doença de Newcastle (amostra La Sota) no $7^{\circ}$ e no $21^{\circ}$ dia de idade. As temperaturas máximas e mínimas registradas durante todo o período experimental foram 30,87 e $26,34^{\circ} \mathrm{C}$, respectivamente, e a umidade relativa do ar, de $71 \%$.

O delineamento experimental utilizado foi o inteiramente casualizado, em arranjo fatorial 4 x 4 (níveis de PB x níveis de EM), com três repetições e 16 aves por unidade experimental. As rações experimentais foram formuladas com base na composição dos ingredientes (Rostagno et al., 2000) e nas exigências nutricionais de codornas (NRC, 1994), exceto para a PB e EM, e resultaram das combinações dos níveis de proteína $(20,22,24$ e $26 \%$ de PB) e energia $(2.565,2.715,2.865$ e $3.015 \mathrm{kcal}$ de EM/kg), conforme descrito na Tabela 1 .

No período total de criação, foram avaliados o consumo de ração (g/ave), o ganho de peso (g/ave) e a conversão alimentar $(\mathrm{g} / \mathrm{g})$ das aves e a viabilidade econômica das rações (\%). Os dados foram analisados pelo procedimento Proc GLM (SAS, 2000), efetuando-se o estudo dos efeitos dos níveis de PB e EM e de suas interações por meio da análise de regressão. Os graus de liberdade dos fatores avaliados foram desdobrados nos efeitos lineares, quadráticos e cúbicos para escolha do modelo de regressão que melhor descrevesse o comportamento dos dados. 


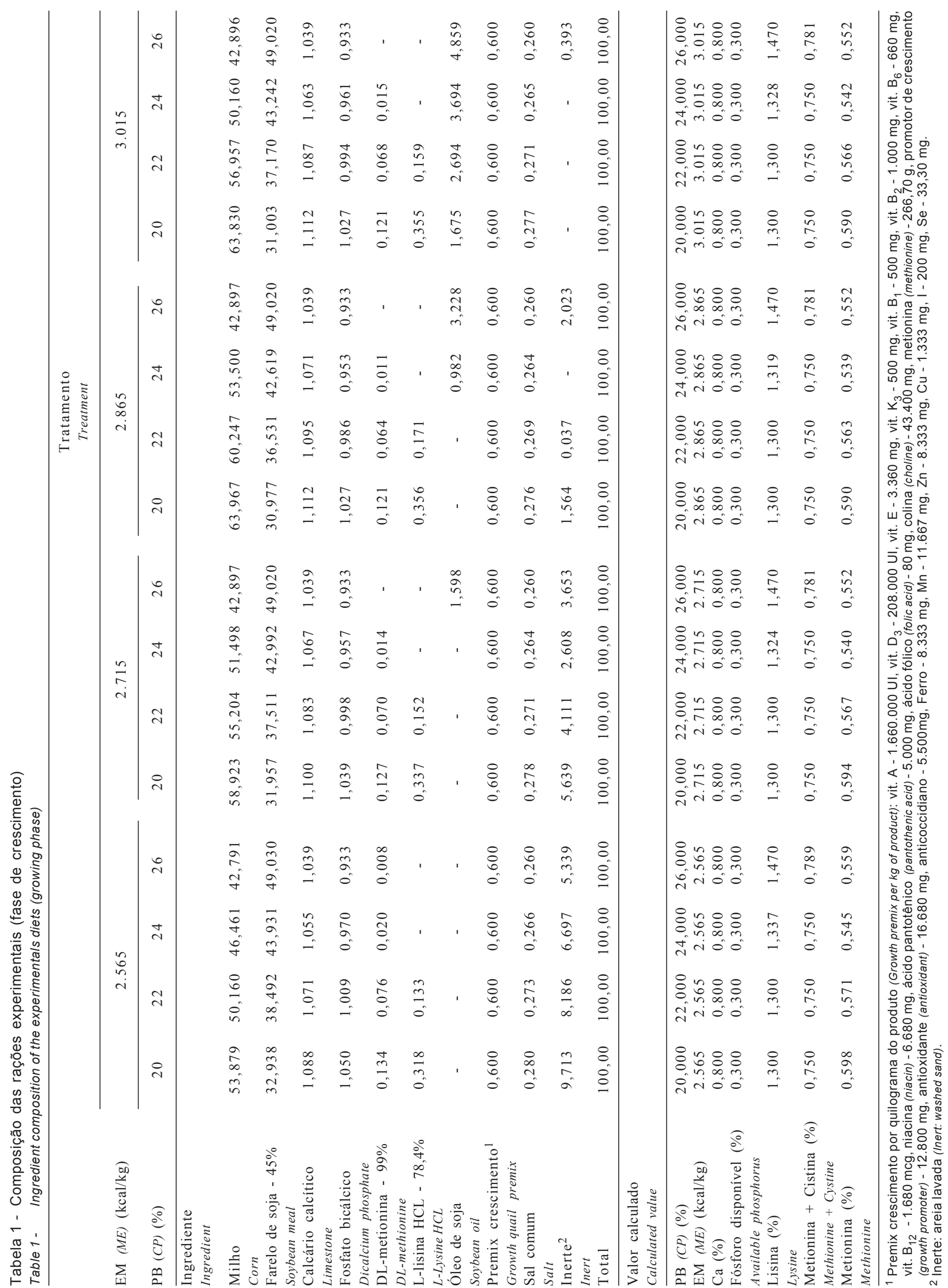




\section{Resultados e Discussão}

Como descrito na Tabela 2, constatou-se, pelas análises estatísticas, que não houve interações significativas $(\mathrm{P}>0,05)$ níveis de proteína $\times$ níveis de energia para as características estudadas.

O consumo de ração (Tabela 2) foi influenciado significativamente $(P \leq 0,01)$ apenas pelo nível de EM da ração. A análise de regressão comprovou que o consumo de ração diminuiu linearmente $\left(\hat{Y}=1606,085-0,247 X ; R^{2}=0,52\right)$ com o aumento do nível de EM da ração. De acordo com a equação, para cada kcal de aumento na energia, houve redução de $0,247 \mathrm{~g}$ no consumo de ração por ave.

Segundo Rostagno (1975) e Leeson et al. (1996), os animais tendem a regular o consumo de ração de forma a ingerir quantidade constante de energia. Por isso, alteram o consumo de ração de acordo com o nível de energia. Os resultados obtidos nessa pesquisa indicam que as codornas de corte se alimentaram para satisfazer, primeiramente, suas exigências de energia, comportamento semelhante ao dos frangos de corte (Albino \& Silva, 1996; Sakomura, 1996). Esses resultados também corroboram a teoria quimiostática da ingestão de alimentos (Murakami et al., 1993; Ávila et al., 2003).

Neste estudo, os diferentes níveis de proteína das rações não influenciaram o consumo de ração. Trabalhando com codornas de corte alimentadas com rações isoenergéticas $(2.900 \mathrm{kcal}$ de $\mathrm{EM} / \mathrm{kg}$ ) e com níveis de proteína iguais aos desse experimento, Oliveira (2001a) também não encontrou efeito dos níveis de proteína sobre o consumo de ração. Os resultados obtidos para o efeito da proteína da ração no controle da ingestão de alimento por codornas corroboram os observados por de Olomu \& Offiong (1980), que constataram que o nível de proteína da ração exerce pouco ou nenhum efeito sobre o consumo total de ração por frangos de corte em fase de crescimento. Entretanto, os resultados descritos por Sklan \& Plavnik (2002) indicaram que, em rações com os mesmos níveis de metionina + cistina e lisina, o aumento do nível de (PB) da ração resultou em menor consumo pelos frangos no período de 1 a 4 semanas de idade. Por outro lado, quando mantidas as relações aminoácidos/proteína, o consumo aumentou até atingir um platô. Segundo os autores, não somente a concentração de proteína da ração, mas a de um ou de vários aminoácidos, pode estar envolvida na regulação do consumo, semelhante ao que acontece com ratos. De acordo com Gonzales (2002), a ação da proteína no controle do consumo não resulta somente da quantidade de proteína, mas também de sua qualidade, isto é, da concentração e do balanceamento dos aminoácidos. Nesse experimento, nas rações com níveis mais baixos de PB, os aminoácidos lisina e metionina foram adicionados para atender às exigências mínimas sugeridas pelo NRC (1994), o que pode ter contribuído para estes resultados.

Não foi observado efeito dos níveis de proteína sobre o ganho de peso (Tabela 2). Esses resultados confirmam os obtidos por Oliveira (2001a), que, trabalhando com níveis de PB iguais aos desse experimento em rações isoenergéticas $(2.900 \mathrm{kcal} \mathrm{EM} / \mathrm{kg})$, não observou efeito dos níveis de proteína da ração sobre o ganho de peso de codornas de corte. Almeida (2001) também não notou efeito dos níveis de proteína da ração sobre o desempenho de codornas italianas. Entretanto, Oliveira et al. (2002), testando cinco níveis de proteína $(18,20,22,24$ e $26 \%)$ e três de energia

Tabela 2 - Consumo de ração (g/ave/dia), ganho de peso (g/ave), conversão alimentar (g/g) e viabilidade econômica (\%) obtidos nos tratamentos

Table 2 - Feed intake (g/bird), weight gain (g/bird), feed:gain ratio $(\mathrm{g} / \mathrm{g})$ and viability $(\%)$ as affected by the treatments

\begin{tabular}{|c|c|c|c|c|c|}
\hline $\begin{array}{l}\text { Variável } \\
\text { Item }\end{array}$ & & $\begin{array}{l}\text { Consumo de ração }{ }^{1} \\
\text { Feed intake }\end{array}$ & $\begin{array}{l}\text { Ganho de peso } \\
\text { Weight gain }\end{array}$ & $\begin{array}{c}\text { Conversão alimentar } \\
\text { Feed:gain ratio }\end{array}$ & $\begin{array}{l}\text { Viabilidade }(\%) \\
\text { Viability }(\%)\end{array}$ \\
\hline \multirow{4}{*}{$\begin{array}{l}\text { Proteína bruta (\%) } \\
\text { Crude protein (\%) }\end{array}$} & 20 & 870 & 255 & 3,41 & 97,40 \\
\hline & 22 & 873 & 251 & 3,48 & 96,88 \\
\hline & 24 & 888 & 253 & 3,52 & 98,96 \\
\hline & 26 & 906 & 252 & 3,61 & 98,44 \\
\hline \multirow{4}{*}{$\begin{array}{l}\text { Energia (kcal EM/kg) } \\
\text { Energy (kcal ME/kg) }\end{array}$} & 2.565 & 937 & 248 & 3,78 & 98,96 \\
\hline & 2.715 & 911 & 253 & 3,61 & 96,36 \\
\hline & 2.865 & 858 & 254 & 3,38 & 98,44 \\
\hline & 3.015 & 831 & 256 & 3,24 & 97,92 \\
\hline CV (\%) & & 4,43 & 2,97 & 4,01 & 3,32 \\
\hline Proteína (Protein) & & n.s & n.s & n.s & n.s \\
\hline Energia (Energy) & & $P d " 0,01 * L$ & $\mathrm{Pd} " 0,05 * \mathrm{~L}$ & $\mathrm{Pd} " 0,01 * \mathrm{~L}$ & n.s \\
\hline Proteína $\mathrm{x}$ energia (Protein $x$ energy) & & n.s & n.s & n.s & n.s \\
\hline
\end{tabular}

${ }^{*}$ Efeito linear (linear effect).

n.s. Não-significativo $(P \leq 0,05)$ (Not significant, $P \leq 0.05)$. 
$(2.800,3.000$ e $3.200 \mathrm{kcal}$ de EM/ $/ \mathrm{kg})$ para codornas, verificaram que, para o máximo ganho de peso no período total de 5 a 49 dias de idade, as rações deveriam conter $26 \%$ de PB e $3.200 \mathrm{kcal} \mathrm{de} \mathrm{EM/kg}$.

A análise dos dados de ganho de peso (Tabela 2) comprovou que apenas os níveis de EM nas rações influenciaram $(\mathrm{P} \leq 0,05)$ essa variável. A análise de regressão mostrou que o ganho de peso aumentou linearmente ( $\left.\hat{\mathrm{Y}}=202,731+0,017 \mathrm{X} ; \mathrm{R}^{2}=0,13\right)$ com o acréscimo do nível da EM da ração. De acordo com a equação, para cada kcal de aumento na energia, houve acréscimo de $0,017 \mathrm{~g}$ no ganho de peso das aves durante o período estudado.

Embora não tenha havido diferença significativa pelo teste de comparação de médias, o maior ganho de peso foi observado para as aves que receberam ração com nível mais alto de energia (3.015 kcal de EM/kg). Essas aves ganharam, em média, 8,26 g a mais que as alimentadas com o nível de $2.565 \mathrm{kcal} \mathrm{de} E M / \mathrm{kg}$. Esse aumento no ganho de peso ocasionado pelo acréscimo do nível de energia da ração também foi observado por Oliveira et al. (2002) e tem sido atribuído ao aumento da ingestão de energia, visto que a regulação do consumo pelo nível de energia da ração não é um mecanismo perfeito. Essa informação pode ser confirmada pelos resultados obtidos para ingestão de energia, que aumentou com o incremento da energia da ração. As aves alimentadas com as rações mais energéticas também apresentaram maior ganho de peso, como resultado dos benefícios proporcionados pelo efeito extracalórico das gorduras quando o aumento da energia foi obtido com a inclusão de óleo nas rações (NRC, 1994).

Como demonstrado na Tabela 2, a conversão alimentar não foi influenciada $(\mathrm{P}>0,05)$ pelo nível de proteína da ração, não sendo observada interação níveis de proteína $\times$ níveis de energia para esta variável. Cheng et al. (1997) constataram redução no aproveitamento da proteína para o ganho de peso com o aumento da quantidade de proteína na ração de frangos de corte. Segundo Leeson (1995), a redução da eficiência do uso da proteína ocorre porque a síntese muscular é geneticamente controlada, havendo, portanto, um limite para a deposição diária de proteína, independentemente de sua ingestão. De acordo com Sklan \& Plavnik (2002), rações para frangos de corte devem ser formuladas para fornecer aminoácidos suficientes para síntese protéica, de modo que o excesso de aminoácidos pode diminuir a eficiência de utilização dos aminoácidos essenciais. A redução no desempenho e na eficiência alimentar com o aumento da ingestão de $\mathrm{PB}$ pode ser atribuída à menor eficiência de uso dos aminoácidos excedentes, visto que o excesso de proteína, ou de aminoácidos ingeridos, é catabolizado na forma de ácido úrico gerando um custo energético para que esse processo ocorra. Esse custo é relativamente alto, pois o gasto de energia para incorporar um aminoácido na cadeia protéica é estimado em torno de 4 mols de ATP e, para excretar um aminoácido, são gastos de 6 a 18 mols de ATP, desviando para a excreção de $\mathrm{N} \mathrm{a}$ energia que deveria ser utilizada para manutenção corporal (Leclercq, 1996, citado por Costa et al., 2001).

A análise de regressão comprovou que a conversão alimentar melhorou linearmente $(\hat{\mathrm{Y}}=7,072-0,001 \mathrm{X}$; $\left.\mathrm{R}^{2}=0,64\right)(\mathrm{P} \leq 0,01)$ com o aumento do nível de EM da ração. De acordo com a equação obtida, para cada kcal de aumento na energia da ração, houve redução média de 0,001 pontos na conversão alimentar. Ávila et al. (2003) observaram, com o aumento da EM da ração, melhora na conversão alimentar de codornas destinadas à produção de carne e recomendaram o nível de $3.050 \mathrm{kcal}$ de $\mathrm{EM} / \mathrm{kg}$.

A melhora na conversão alimentar de frangos de corte com o aumento da energia da ração tem sido observada com freqüência. De acordo com Leeson et al. (1996), o aumento da energia da ração promove redução no consumo e, como o ganho de peso não é alterado, as aves alimentadas com as rações mais energéticas apresentam melhor conversão alimentar. Considerando que a energia é o item de maior custo de rações para aves (Nascimento et al., 2002) e que o aumento no custo da ração com o incremento da energia deve ser compensado pela melhora no desempenho das aves, pode-se recomendar o nível mínimo de $2.865 \mathrm{kcal} \mathrm{EM} / \mathrm{kg}$ para rações de codornas de corte no período de 1 a 42 dias.

Não foram observados efeitos significativos dos níveis de proteína e energia ou de sua interação sobre a viabilidade econômica das rações (Tabela 2).

Durante toda a fase experimental, foram registradas 16 mortes $(2,08 \%)$. Após necrópsia das aves para investigação da causa mortis, concluiu-se que a maioria das mortes decorreu de acidentes ocorridos nos primeiros dias de vida das aves, e não por efeito das rações utilizadas.

Estudos sobre a viabilidade de produção de codornas são escassos. Entretanto, pode-se considerar baixo o índice de mortalidade $(2,08 \%)$ observado na fase de crescimento das codornas, pois foi inferior aos obtidos por diversos pesquisadores em experimentos com codornas de corte Oliveira (2001a), de 3,3\% - e com codornas de postura Panda \& Shrivastav (1978), 8,78\%; Mohan et al. (1990), 9,48\%; e Oliveira (1999), 3,3\%.

\section{Conclusões}

O consumo de ração por codornas de corte é regulado pela quantidade de energia da ração. 
O aumento da energia metabolizável das rações por meio da adição de óleo resulta em melhor conversão alimentar.

Rações para codornas européias destinadas à produção de carne podem ser formuladas com $20 \%$ de PB e $2.865 \mathrm{kcal}$ de $\mathrm{EM} / \mathrm{kg}$.

\section{Literatura Citada}

ALBINO, L.F.T.; SILVA, M.A. Valores nutritivos de alimentos para aves e suínos determinados no Brasil. In: SIMPÓSIO INTERNACIONAL SOBRE EXIGÊNCIAS NUTRICIONAIS DE AVES E SUÍNOS, 1996, Viçosa, MG. Anais... Viçosa, MG: Universidade Federal de Viçosa, 1996. p.303-318.

ALMEIDA, M.I.M. Efeito de linhagem e de nível protéico sobre o desempenho e características de carcaças de codornas (Coturnix $s p$ ) criadas para corte. Botucatu: Universidade Estadual Paulista, 2001. 135p. Tese (Doutorado em Ciências Biológicas) - Universidade Estadual Paulista, 2001.

ÁVILA, R.P.; SOARES, R.T.R.N.; CORDEIRO, M.D. et al. et al. Níveis de energia para codornas japonesas na fase de crescimento. In: REUNIÃO ANUAL DA SOCIEDADE BRASILEIRA DE ZOOTECNIA, 40., 2003, Santa Maria. Anais... Santa Maria: Sociedade Brasileira de Zootecnia, 2003.

CHENG, T.K.; HAMRE, M.L.; COON, C.N. et al. Responses of broiler to dietary protein levels and amino acid supplementation to low protein diets at various environmental temperature. Journal Applied Poultry Research, v.6, p.1833, 1997.

COSTA, F.G.P.; ROSTAGNO, H.S.; ALBINO, L.F.T. et al. Níveis dietéticos de proteína bruta para frangos de corte de 1 a 21 e 22 a 42 dias de idade. Revista Brasileira de Zootecnia, v.30, n. 5, p.1498-1505, 2001 .

GARCIA, E.A. Codornas para a produção de carne. In: SIMPÓSIO INTERNACIONAL DE COTURNICULTURA, Lavras, 1., 2002, Lavras. Anais... Lavras: Universidade Federal de Lavras, 2002. p.97-108.

GONZALES, E. Ingestão de alimentos: mecanismos regulatórios. In: MACARI, M.; FURLAN, R.L.; GONZALES, E. (Eds.). Fisiologia aviária aplicada a frangos de corte. Jaboticabal: FUNEP, 2002. p.187-199.

LEESON, S. Nutrição e qualidade de carcaça de frangos de corte. In: CONFERÊNCIA APINCO DE CIÊNCIA E TECNOLOGIA AVÍCOLAS, 1995, Curitiba. Anais... Curitiba: Fundação Apinco de Ciência e Tecnologia Avícolas, 1995. p.11-18.

LEESON, S.; YERSIN, A.; VOLKER, L. et al. Broiler response to energy or energy and protein dilution in the finisher diet. Poultry Science, v.75, p.522-528, 1996.

MARTINS, E.N. Perspectivas do melhoramento genético de codornas no Brasil. In: SIMPÓSIO INTERNACIONAL DE COTURNiCUltura, Lavras, 1., 2002, Lavras. Anais... Lavras: Universidade Federal de Lavras, 2002. p.109-112.

MOHAN, B.; REDDY, P.R.; NARAHARI, D. et al. Effect of feeding different vegetable proteins on the performance of japanese quail. Indian Journal of Poultry Science, v.25, n.3, p.178$182,1990$.

MURAKAMI, A.E.; MORAES, V.M.B.; ARIKI, J. et al. Níveis de proteína e energia em rações para codornas japonesas (Coturnix coturnix japonica) em crescimento. Revista da Sociedade Brasileira de Zootecnia, v. 22, n.4, p.534-540, 1993.

MURAKAMI, A.E.; ARIKI, J. Produção de codornas japonesas. Jaboticabal: FUNEP, 1998. 79p.

NASCIMENTO, A.H.; GOMES, P.C.; ALBINO, L.F.T. et al. Composição química e valores de energia metabolizável das farinhas de penas e vísceras determinados por diferentes metodologias para aves. Revista Brasileira de Zootecnia, v.31, n.3, p.1409-1417, 2002 (supl.).
NATIONAL RESEARCH COUNCIL - NRC. Nutrient requirements of domestic animals. 9.rev.ed. Washington, D.C.: National Academy Press, 1994. 155p.

OLIVEIRA, E.G. Pontos críticos no manejo e nutrição de codornas. In: SIMPÓSIO SOBRE MANEJO E NUTRIÇÃO DE AVES E SUÍNOS E TECNOLOGIA DA PRODUÇÃO DE RAÇÕES, 2001, Campinas. Anais... Campinas: Colégio Brasileiro de Nutrição Animal, 2001a. p.71-96.

OLIVEIRA, E.G. Avaliação do desempenho, rendimento de carcaça e das características químicas e sensoriais de codornas para corte. Botucatu: Universidade Estadual Paulista, 2001. 96p. Tese (Doutorado em Zootecnia) - Universidade Estadual Paulista, 2001b.

OLIVEIRA, M.A. O desempenho produtivo e econômico da codorna (Coturnix coturnix japonica) submetida a diferentes rações comerciais. Recife: Universidade Federal Rural de Pernambuco, 1999. 77p. Dissertação (Mestrado em Zootecnia) - Universidade Federal Rural de Pernambuco, 1999.

OLIVEIRA, N.T.E.; SILVA, M.A.; SOARES, R.T.R.N. et al. Exigência de proteína bruta e energia metabolizável para codornas japonesas criadas para a produção de carne. Revista Brasileira de Zootecnia, v.31, n.2, p.675-686, 2002.

OLOMU, J.M.; OFFIONG, S.A. The effects of different protein and energy levels and time of change from starter to finisher ration on the performance of broiler chickens in the tropics. Poultry Science, v.59, p.828-835, 1980.

PANDA, B.; SHRIVASTAV, A.K. Protein requirement of start japanese quail (Coturnix coturnix japonica). In: CONGRESSO MUNDIAL DE AVICULTURA, 16., 1978, Rio de Janeiro. Anais... Rio de Janeiro: Associação Mundial de Ciência Avícola, Secção Brasileira, 1978. p.1347-1349.

PINTO, R.; FERREIRA, A.S.; ALBINO, L.F.T. et al. Níveis de proteína e energia para codornas japonesas em postura. Revista Brasileira de Zootecnia, v. 31, n.4, p.1761-1770,2002.

ROSTAGNO, H.S. Alimentação de frangos de corte para máximo crecimento e melhor conversão alimentar. In: CURSO DE ATUAliZAÇÃO AVÍCOLA, 1., 1975, Belo Horizonte. Anais... Belo Horizonte: Editora Fundação Cargill, 1975. p.309-338.

ROSTAGNO, H.S.; ALBINO, L.F.T.; DONZELE, J.L. et al. Composição de alimentos e exigências nutricionais de aves e suínos (Tabelas Brasileiras). Viçosa, MG: Universidade Federal de Viçosa, 2000. 141p.

SAKOMURA, N.K. Exigências nutricionais das aves utilizando o modelo fatorial. In: SIMPÓSIO INTERNACIONAL SOBRE EXIGÊNCIAS NUTRICIONAIS DE AVES E SUÍNOS, 1996, Viçosa, MG. Anais... Viçosa, MG: Universidade Federal de Viçosa, 1996. p.319-344

STATISTICAL ANALYSIS SYSTEM - SAS. SAS Users' guide: statistics. version 8. Cary: 2000.

SHRIVASTAV, A.K.; PANDA, B. A review of quail nutrition research in India. World's Poultry Science Journal, v.55, n.3, p.73$81,1999$.

SILVA, J.H.V. et al. Efeitos do plano de nutrição e do sexo sobre o rendimento de carcaça de codornas tipo carne. In: REUNIÃO ANUAL DA SOCIEDADE BRASILEIRA DE ZOOTECNIA, 40. 2003, Santa Maria. Anais... Santa Maria: Sociedade Brasileira de Zootecnia, 2003.

SKLAN, D.; PLAVNIK, I. Interactions between dietary crude protein and essential amino acid intake on performance in broilers. British Poultry Science, v.43, p.442-449, 2002. 